\title{
Gallium ions promote osteoinduction of human and mouse osteoblasts via the TRPM7/Akt signaling pathway
}

\author{
MINGYANG YU $^{1 *}$, YUNGUANG WANG $^{2 *}$, YAO ZHANG $^{1}$, DAPING CUI ${ }^{1}$, GUISHAN GU $^{3}$ and DEWEI ZHAO ${ }^{1}$ \\ ${ }^{1}$ Department of Orthopedics, Affiliated Zhongshan Hospital of Dalian University, Dalian, Liaoning 116001; \\ ${ }^{2}$ Laboratory of Molecular Biology, Institute of Nuclear-Agricultural Sciences, Zhejiang University, Hangzhou, \\ Zhejiang 310058; ${ }^{3}$ Department of Orthopedics, The First Hospital of Jilin University, Changchun, Jilin 130021, P.R. China
}

Received November 28, 2019; Accepted June 19, 2020

DOI: $10.3892 / \mathrm{mmr} .2020 .11346$

\begin{abstract}
Gallium (Ga) ions have been widely utilized for biomedical applications; however, their role in osteoblast regulation is not completely understood. The aim of the present study was to investigate the potential effect of Ga ions on osteoinduction in two osteoblast cell lines and to explore the underlying mechanisms. Human hFOB1.19 and mouse MC3T3-E1 osteoblasts were treated with Ga nitride (GaN) at different concentrations, and the degree of osteoinduction was assessed. Ga ion treatment was found to increase alkaline phosphatase activity and accelerate calcium nodule formation, as assessed using ALP activity assay and Alizarin red S staining. Moreover, upregulated expression levels of osteogenic proteins in osteoblasts were identified using western blotting and reverse transcription-quantitative PCR. Western blotting was also performed to demonstrate that the biological action of $\mathrm{Ga}$ ions was closely associated with the transient receptor potential melastatin 7/Akt signaling pathway. Furthermore, it was found that Ga ions did not cause osteoblast apoptosis, as indicated via flow cytometry, but promoted osteoclast proliferation, migration or invasion. The present study investigated the potential role of $\mathrm{Ga}$ ions in regulating osteoinduction of osteoblasts, thereby providing a promising strategy for the treatment of osteoporosis.
\end{abstract}

Correspondence to: Dr Dewei Zhao, Department of Orthopedics, Affiliated Zhongshan Hospital of Dalian University, 6 Jiefang Street, Dalian, Liaoning 116001, P.R. China

E-mail: zhaodewei2016@163.com

Dr Guishan Gu, Department of Orthopedics, The First Hospital of Jilin University, 71 Xinmin Street, Changchun, Jilin 130021, P.R. China

E-mail: guguishan001@163.com

${ }^{*}$ Contributed equally

Key words: gallium, osteoinduction, osteoblasts, transient receptor potential melastatin 7 , osteoporosis

\section{Introduction}

Gallium $(\mathrm{Ga})$ is a semi-metallic element that has been explored for a variety of biomedical applications, including disease diagnosis and treatment of metabolic bone diseases, different types of cancer and inflammatory diseases (1). The applications of the element are primarily attributed to its unique characteristics and functionalities, which include decreasing accelerated bone mineral resorption and lowering associated elevated plasma calcium levels $(2,3)$. In particular, the discovery of the antihypercalcemic effect of $\mathrm{Ga}$, which results from the inhibition of bone resorption rather than the increment of urinary calcium excretion, attracted considerable research interest in exploring its bone-related activity $(4,5)$. The antiresorptive ability of $\mathrm{Ga}$ also contributes to the suppression of osteolysis and bone pain associated with multiple myeloma and bone metastases (6), as well as the effective treatment of Pagets bone disease (7). Previous studies using in vitro bone fragment models or in vivo implant rodent models have demonstrated that $\mathrm{Ga}$ ions often display a pronounced affinity for bone surfaces and, thus, affect both bone cells and tissues (8-10). For example, Verron et al (10) reported that Ga ions can inhibit the differentiation and resorbing activity of osteoclasts in a dose-dependent manner, without affecting osteoblast viability and proliferation. Therefore, the aforementioned studies suggest the therapeutic potential of $\mathrm{Ga}$ for bone-related diseases; however, further investigation is required.

Osteoporosis is a common bone disorder characterized by reduced bone mass, impaired bone strength and altered bone architecture, which often leads to increased skeletal fragility and high-stakes fractures (11-13). Osteoporosis is primarily caused by several factors, such as increasing age, estrogen or androgen deficiency, rheumatoid arthritis, low body mass index and excessive use of certain drugs (14). The disorder is characterized by an unbalanced increase in bone turnover, with bone resorption exceeding bone formation, which may be attributed to the increased number of osteoclasts or excessive osteoclast activity that induce osteolysis (15-17). In addition to hyperactive osteolysis, decreased osteogenesis is another pathological characteristic observed in patients with osteoporosis (18). Therefore, an approach involving both inhibition of excessive osteoclast osteolysis and simultaneous promotion of osteoblast osteogenesis may serve as an optimal strategy for 
patients with severe bone loss (19). However, the development of effective drugs to simultaneously inhibit osteoclastogenesis while promoting osteoblastogenesis for the treatment of osteoporosis remains a challenge.

The primary purpose of the present study was to investigate the effect of Ga ions on osteoinduction of osteoblasts and to explore the underlying biological mechanisms. The osteogenic differentiation of two osteoblast cell lines after treatment with $\mathrm{Ga}$ nitride $(\mathrm{GaN})$ at the optimized concentration was evaluated by measuring alkaline phosphatase (ALP) activity, calcium nodule formation and the expression levels of osteogenesis-related proteins. The effect of $\mathrm{Ga}$ ions on osteoblast migration and invasion was also investigated. The results demonstrated that $\mathrm{Ga}$ ions effectively promoted osteogenic differentiation, and osteoblast migration and invasion. By investigating the underlying molecular mechanisms, the results suggested that transient receptor potential melastatin 7 (TRPM7) was involved in Ga ion-mediated regulation of osteoblast osteoinduction.

\section{Materials and methods}

Cell culture. A human osteoblast cell line hFOB1.19 and mouse MC3T3-E1 pre-osteoblast cells were purchased from American Type Culture Collection. hFOB1.19 cells were cultured in DMEM (Gibco; Thermo Fisher Scientific, Inc.) supplemented with 10\% FBS (Gibco; Thermo Fisher Scientific, Inc.), $100 \mathrm{U} / \mathrm{ml}$ penicillin and $100 \mu \mathrm{g} / \mathrm{ml}$ streptomycin. MC3T3-E1 cells were cultured in Minimum Essential Medium (Gibco; Thermo Fisher Scientific, Inc.) containing $10 \% \mathrm{FBS}, 100 \mathrm{U} / \mathrm{ml}$ penicillin, $100 \mu \mathrm{g} / \mathrm{ml}$ streptomycin and $1 \% \mathrm{~L}$-glutamine. All cells were cultured at $37^{\circ} \mathrm{C}$ with $5 \%$ $\mathrm{CO}_{2}$ in a humidified incubator. The cell culture medium was replaced every 2 days. Mouse MC3T3-E1 cells are pre-osteoblasts and were cultured in osteoinduction medium $(50 \mathrm{mg} / \mathrm{ml}$ $\beta$-glycerophosphate and $10 \mathrm{mM} \mathrm{L-ascorbic} \mathrm{acid).}$

Design of TRPM7 siRNAs and transfection. TRPM7 siRNA and negative control siRNA were purchased from Santa Cruz Biotechnology, Inc. Cells $\left(5 \times 10^{5}\right.$ cells/well) into 6-well were transfected with $50 \mathrm{pmol} / \mathrm{ml}$ siRNA using Lipofectamine ${ }^{\circledR} 2000$ (Thermo Fisher Scientific, Inc.) according to the manufacturers instructions. The siRNA sequences are listed in Table I. Following transfection for 72 or $96 \mathrm{~h}$, cells were used for subsequent experiments. In total, three siRNA specific to TRPM7 and a non-specific siRNA specific to TRPM7 were obtained from GenaPharma (Shanghai, China). The three siRNA specific to TRPM7 were compared with TRPM7 non-specific siRNA, and it was found that TRPM7 siRNA2 had the strongest knockout effect.

Antibodies and western blot analysis. Western blotting was performed as previously described (20). The following primary antibodies were used: Anti-GAPDH (Abcam; cat. no. ab181602; 1:1,000), anti-Osterix (Abcam; cat. no. ab22552; 1:1,000), anti-osteocalcin (OCN; Abcam; cat. no. ab93876; 1:1,000), anti-matrix metallopeptidase (MMP)2 (Abcam; cat. no. ab97779; 1:1,000), anti-MMP9 (Abcam; cat. no. ab58803; 1:500), anti-Akt (Cell Signaling Technology, Inc.; cat. no. 4691; 1:1,000), anti-phosphorylated
(p)-Akt (Cell Signaling Technology, Inc.; cat. no. 4060; 1:1,000), anti-Runt-related transcription factor 2 (Runx2; Cell Signaling Technology, Inc.; cat. no. 12556; 1:1,000), anti-Na/K ATPase (Cell Signaling Technology, Inc.; cat. no. 3010; 1:1,000), anti-osteopontin (OPN; Santa Cruz Biotechnology, Inc.; cat. no. SC-21742; 1:1,000) and anti-TRPM7 (Affinity Biosciences; cat. no. DF7513; 1:1,000). Western blot images were obtained using a Molecular Imager ${ }^{\circledR}$ (Bio-Rad Laboratories, Inc.). Protein expression levels were measured via densitometry analysis (ImageJ, v 1.8.0_112; National Institutes of Health) with GAPDH as the loading control.

Reverse transcription-quantitative PCR (RT-qPCR). Total RNA was extracted from cells using TRIzol ${ }^{\circledR}$ (Thermo Fisher Scientific, Inc.) according to the manufacturers protocol. Total RNA was reverse transcribed into cDNA using PrimeScript $^{\mathrm{TM}}$ RT Master Mix (cat. no. RR036Q; Takara Bio, Inc.). Subsequently, qPCR was performed using a StepOne Plus Real-Time PCR Detection system (7500ABI; Applied Biosystems; Thermo Fisher Scientific, Inc.) and TB GreenTM Premix Ex Taq ${ }^{\mathrm{TM}}$ II (Tli RNaseH Plus; cat. no. RR820Q; Takara Bio, Inc.). PCR cycling conditions were a follows: One cycle at $50^{\circ} \mathrm{C}$ for $2 \mathrm{~min}$ and one cycle at $95^{\circ} \mathrm{C}$ for $10 \mathrm{~min}$, a two-step PAC procedure was used consisting of $15 \mathrm{sec}$ at $95^{\circ} \mathrm{C}$ and $1 \mathrm{~min}$ at $60^{\circ} \mathrm{C}$ for 45 cycles. The primers used for qPCR are presented in Table II. mRNA expression levels were quantified using the $2^{-\Delta \Delta C \mathrm{C}}$ method (21).

ALP activity assay. hFOB1.19 and MC3T3-E1 cells $\left(5 \times 10^{4}\right.$ cells/well) were seeded in 24-well plates and cultured overnight at $37^{\circ} \mathrm{C}$ for cell attachment. The cell culture medium in each well was carefully removed, and fresh osteogenic induction medium (DMEM-F12; Gibco; Thermo Fisher Scientific, Inc.) supplemented with $50 \mathrm{mg} / \mathrm{ml} \beta$-glycerophosphate, $10 \mathrm{mM}$ L-ascorbic acid and different concentrations $\left(10^{-7}-10^{-2} \mathrm{M}\right)$ of GaN (Shanghai Aladdin Bio-Chem Technology Co., Ltd.) was added to each well. Following culture for 7 days at $37^{\circ} \mathrm{C}$, cells were washed twice with PBS, scraped off the plates and collected into tubes. ALP activity was measured using the Sensolyte ${ }^{\circledR}$ pNPP Alkaline Phosphatase Assay kit (AnaSpec) according to the manufacturers instructions. Briefly, $980 \mu 1$ reaction buffer was added into a new tube, and $960 \mu \mathrm{l}$ reaction buffer was added into the test tube and enzyme control tube. Subsequently, $20 \mu \mathrm{l}$ pNPP solution $(0.67 \mathrm{M})$ was added to each tube and equilibrated at $37^{\circ} \mathrm{C}$. Then, $20 \mu \mathrm{l}$ sample was added into the test tube and $20 \mu \mathrm{l}$ diluted ALP solution added into the enzyme control tube. The mixture was immediately mixed and the absorbance of each tube was measured at a wavelength of $405 \mathrm{~nm}$ using an enzyme standard instrument (Thermo Fisher Scientific, Inc.) within 5 min to obtain the maximum linear rate of the test $(\Delta \mathrm{A} 405 \mathrm{~nm} / \mathrm{min})$.

Cell proliferation assay. MC3T3-E1 and hFOB1.19 cells were seeded $\left(5 \times 10^{3}\right.$ cells/well) into 96-well plates and cultured for $24 \mathrm{~h}$ at $37^{\circ} \mathrm{C}$ with $5 \% \mathrm{CO}_{2}$ in a humidified incubator. MC3T3-E1 cells were treated with $\mathrm{GaN}\left(10^{-4} \mathrm{M}\right)$ and TRPM7 siRNA or LY294002 (APExBIO Technology; $10 \mu \mathrm{M}$ ) for 0,7 or 14 days at $37^{\circ} \mathrm{C}$. hFOB1.19 cells were treated with $\mathrm{GaN}\left(10^{-4} \mathrm{M}\right)$ and TRPM7 siRNA or LY294002 (10 $\mu \mathrm{M}$; APExBIO Technology) for 0,3 or 7 days at $37^{\circ} \mathrm{C}$, and without cell pretreatment, effective 
Table I. Sequences of TRPM7 siRNA used for hFOB1.19 and MC3T3-E1 cell transfection.

A, hFOB 1.19

\begin{tabular}{ll}
\hline siRNA & \multicolumn{1}{c}{ Sequence $\left(5^{\prime} \rightarrow 3^{\prime}\right)$} \\
\hline TRPM7 siRNA1 & $\begin{array}{l}\text { F: GCGCUUUCCUUAUCCACUUTT } \\
\text { R: AAUGGAUAAGGAAAGCGCTT }\end{array}$ \\
TRPM7 siRNA2 & $\begin{array}{l}\text { F: CCAUAUCCCACAAUCUCAATT } \\
\text { R: UUGAGAUUGUGGGAUAUGGTT }\end{array}$ \\
TRPM7 siRNA3 & F: GUCUUGCCAUGAAAUACUCUU \\
& R: GAGUAUUUCAUGGCAAGACUU \\
Control siRNA & F: UUCUCCGAACGUGUCACGUTT \\
& R: ACGUGACACGUUCGGAGAATT \\
\hline
\end{tabular}

B, MC3T3-E1

\begin{tabular}{ll}
\hline siRNA & \multicolumn{1}{c}{ Sequence $\left(5^{\prime} \rightarrow 3^{\prime}\right)$} \\
\hline TRPM7 siRNA1 & F: GCGCUUUCCUUAUCCACUUTT \\
& R: AAUGGAUAAGGAAAGCGCTT \\
TRPM7 siRNA2 & F: CCAUAUCCCACAAUCUCAATT \\
& R: UUGAGAUUGUGGGAUAUGGTT \\
TRPM7 siRNA4 & F: GGUGUUCCCAGAAAGGCAATT \\
& R: UUGCCUUUCUGGGAACACCTT \\
Control siRNA & F: UUCUCCGAACGUGUCACGUTT \\
& R: ACGUGACACGUUCGGAGAATT
\end{tabular}

siRNA, small interfering RNA; TRPM7, transient receptor potential melastatin 7; F, forward; R, reverse.

concentrations of TRPM7 siRNA and LY294002 were always maintained in the medium. Subsequently, cells were washed with PBS and $20 \mu \mathrm{l}$ Cell Counting Kit-8 (CCK-8) solution (MCE, Inc.) according to the manufacturers instructions in fresh cell culture medium was added to each well. Following incubation at $37^{\circ} \mathrm{C}$ for $4 \mathrm{~h}$, the absorbance of each well was measured at a wavelength of $450 \mathrm{~nm}$ using a microplate reader, which was used to calculate cell proliferation.

Cell apoptosis analysis. hFOB1.19 and MC3T3-E1 cells were seeded $\left(2 \times 10^{5}\right.$ cells/well $)$ into 6 -well cell culture plates and cultured at $37^{\circ} \mathrm{C}$ with $5 \% \mathrm{CO}_{2}$ overnight for attachment. Following cells were treated with $\mathrm{GaN}\left(10^{-4} \mathrm{M}\right)$, cell apoptosis was assessed using the Annexin V-FITC/PI kit (Haigene, Inc.; http://www.haigene.cn/) according to the manufacturers instructions. Briefly, cells were collected and suspended in $500 \mu \mathrm{l}$ buffer. Subsequently, cells were incubated with $5 \mu \mathrm{l}$ Annexin V-FITC and $5 \mu \mathrm{l}$ propidium iodide solution at room temperature for $15 \mathrm{~min}$. Apoptotic cells were measured via flow cytometry (FACSCanto ${ }^{\mathrm{TM}}$ II; BD FACSCanto ${ }^{\mathrm{TM}}$ System $^{\text {F }}$ Software Full v 3.0, BD Biosciences), and early and late apoptosis were assessed.

Alizarin red S staining. To demonstrate the effect of Ga ions on the ability of osteoblasts to produce calcium nodules, Alizarin
Table II. Primers used for reverse transcription-quantitative PCR.

\begin{tabular}{ll}
\hline Gene & \multicolumn{1}{c}{ Sequence $\left(5^{\prime} \rightarrow 3^{\prime}\right)$} \\
\hline Mus Runx2 & F: GACTGTGGTACCGTCATGGC \\
& R: ACTTGGTTTTCATAACAGCGGA \\
Mus Osterix & $\begin{array}{l}\text { F: CCACCAAGAATTACTCAGAACCC } \\
\text { R: AAGGACCGACTCACTCAGTCT }\end{array}$ \\
Mus OCN & F: CGCCTACAAACGCATCTACG \\
(Bglap2) & R: CAGAGAGAGAGGACAGGGAGGA \\
Mus OPN & F: GAGCGAGGATTCTGTGGA \\
& R: TCGACTGTAGGGACGATG \\
Homo MMP2 & F: TGACTTCTTGGATCGGGTCG \\
& R: AAGCACCACATCAGATGACTG \\
Homo MMP9 & F: TGTACCGCTATGGTTACACTCG \\
& R: GGCAGGGACAGTTGCTTCT \\
Homo Runx2 & F: TGGTTACTGTCATGGCGGGTA \\
& R: TCTCAGATCGTTGAACCTTGCTA \\
Homo VEGF & F: GAGGAGCAGTTACGGTCTGTG \\
& R: TCCTTTCCTTAGCTGACACTTGT \\
GAPDH & F: GCACCGTCAAGGCTGAGAAC \\
& R: TGGTGAAGACGCCAGTGGA
\end{tabular}

Runx2, Runt-related transcription factor 2; OCN, osteocalcin; OPN, osteopontin; MMP, matrix metallopeptidase; VEGF, vascular endothelial growth factor.

red S staining was performed. MC3T3-E1 cells cultured $\left(2 \times 10^{5}\right.$ cells/well $)$ in 6 -well cell culture plates were treated with $\mathrm{GaN}\left(10^{-4} \mathrm{M}\right)$ and TRPM7 siRNA or LY294002 $(10 \mu \mathrm{M})$ in osteogenic induction medium for 14 days at $37^{\circ} \mathrm{C}(22)$. Subsequently, cells were fixed with $4 \%$ paraformaldehyde at room temperature for $15 \mathrm{~min}$ and washed three times with PBS. Cells were incubated in Alizarin Red S solution at room temperature for $5 \mathrm{~min}$, followed by washing with distilled water. Stained cells were dried at $60^{\circ} \mathrm{C}$, mounted in xylene for $5 \mathrm{~min}$ and observed using a light microscope (magnification, $\mathrm{x} 400$ ).

Cell migration analysis. Cell migration was assessed using Transwell 24-well cell culture plates with an $8-\mu \mathrm{m}$ pore polycarbonate membrane insert. Briefly, $0.2 \mathrm{ml}$ hFOB1.19 cells $\left(3 \times 10^{5}\right.$ cells $\left./ \mathrm{ml}\right)$ suspended in serum-free DMEM were seeded into the upper chambers and $0.8 \mathrm{ml}$ DMEM supplemented with 10\% FBS was seeded into the lower chambers. Cells were treated with $\mathrm{GaN}\left(10^{-4} \mathrm{M}\right)$ and TRPM7 siRNA or LY294002 $(10 \mu \mathrm{M})$ for $24 \mathrm{~h}$ at $37^{\circ} \mathrm{C}$. Migratory cells were fixed with $70 \%$ ice-cold ethanol for $1 \mathrm{~h}$ at $4^{\circ} \mathrm{C}$, stained with $5 \%$ crystal violet solution for $20 \mathrm{~min}$ at room temperature and counted using a light microscope (magnification, $\mathrm{x} 400$ ).

Cell invasion analysis. Cell invasion was assessed using Transwell 24-well cell culture plates that were precooled at $-20^{\circ} \mathrm{C}$ overnight. Matrigel ${ }^{\circledR}$ was melted at $4^{\circ} \mathrm{C}$ and diluted to a final concentration of $1 \mathrm{mg} / \mathrm{ml}$ with serum-free medium on ice. The upper chambers were precoated with diluted Matrigel ${ }^{\circledR}$ for $4-5 \mathrm{~h}$ at $37^{\circ} \mathrm{C} . \mathrm{hFOB} 1.19$ cells $\left(2.5 \times 10^{5}\right.$ cells $\left./ \mathrm{ml}\right)$ in serum-free 
DMEM/F12 (200 $\mu \mathrm{l})$ containing GaN $\left(10^{-4} \mathrm{M}\right)$ and TRPM7 siRNA or LY294002 $(10 \mu \mathrm{M})$ were seeded into the upper chambers. DMEM $(800 \mu \mathrm{l})$ supplemented with $10 \%$ FBS was seeded into the lower chambers. After incubation for $24 \mathrm{~h}$ at $37^{\circ} \mathrm{C}$, invading cells were fixed with $70 \%$ ice-cold ethanol for $1 \mathrm{~h}$ at $4^{\circ} \mathrm{C}$, stained with $5 \%$ crystal violet solution for $20 \mathrm{~min}$ at room temperature and counted using a light microscope (magnification, $\mathrm{x} 400$ ).

ELISA. Levels of vascular endothelial growth factor (VEGF) protein in media of hFOB1.19 cells were measured using ELISA (Gibco; Thermo Fisher Scientific, Inc.; cat. no. KHG0111), according to the manufacturers instructions.

Statistical analysis. All experiments were performed in triplicate $(\mathrm{n}=3)$. Data are presented as the mean \pm standard deviation. Comparisons among multiple groups were analyzed using one-way ANOVA followed by Tukeys post hoc test. Statistical analyses were performed using SPSS statistical software (version 21.0; IBM Corp.). $\mathrm{P}<0.05$ was considered to indicate a statistically significant difference.

\section{Results}

Ga ions enhance osteoblast ALP activity. Metal elements have been reported to affect the intracellular ALP activity of osteoblast cells in a concentration-dependent manner (23-25). Therefore, the present study investigated the effect of different $\mathrm{Ga}$ ion concentrations on osteoblast ALP activity. Following treatment with $\mathrm{GaN}\left(10^{-7}-10^{-2} \mathrm{M}\right)$ in osteogenic induction medium for 7 days, mouse MC3T3-E1 osteoblasts were examined using an ALP activity assay. Compared with control cells, intracellular ALP activity was significantly increased in cells cultured in osteogenic induction medium. In addition, the ALP activity of GaN-treated cells cultured in osteogenic induction medium increased with increasing $\mathrm{GaN}$ concentration, reaching a maximum level of ALP activity at $10^{-4} \mathrm{M}$ (Fig. 1A). At GaN concentrations above $10^{-4} \mathrm{M}$, ALP activity decreased compared with the $10^{-4} \mathrm{M} \mathrm{GaN}$ group. The effect of Ga ions on the ALP activity of human hFOB1.19 osteoblasts was also investigated by treating cells with different concentrations of GaN $\left(10^{-7}-10^{-2} \mathrm{M}\right)$ for 7 days. Similarly, the ALP activity of hFOB1.19 cells increased with increasing GaN concentrations, reaching a maximum level of ALP activity at $10^{-4} \mathrm{M}$. Furthermore, at $\mathrm{GaN}$ concentrations above $10^{-4} \mathrm{M}$, ALP activity decreased compared with the $10^{-4} \mathrm{M} \mathrm{GaN}$ group (Fig. 1B). The results suggested that Ga ions affect osteoblast ALP activity in a concentration-dependent manner. Based on the aforementioned results, $10^{-4} \mathrm{M} \mathrm{GaN}$ was selected for subsequent experiments, as it was identified as the concentration that induced the highest levels of ALP activity.

Effect of Ga ions on the Akt signaling pathway in osteoblasts. Based on the key roles of the Akt signaling pathway in regulating ALP activity $(26,27)$, the influence of Ga ions on the Akt signaling pathway in osteoblasts was investigated. MC3T3-E1 osteoblasts were cultured in osteogenic induction medium with or without $\mathrm{GaN}\left(10^{-4} \mathrm{M}\right)$ for 0,7 or 14 days. Subsequently, Akt activation and phosphorylation were assessed via western blotting. The results indicated that the levels of p-Akt expression in MC3T3-E1 cells cultured in osteogenic induction medium were markedly higher compared with control cells after 7 and 14 days (Fig. 2A). Furthermore, the expression levels of p-Akt were increased in $\mathrm{GaN}$-treated cells cultured in osteogenic induction medium compared with untreated cells cultured in osteogenic induction medium after 7 and 14 days, particularly after 14 days of incubation. The expression of p-Akt increased in MC3T3-E1 cells in the osteoinduction group in a time-dependent manner compared with osteoinduction $+\mathrm{GaN}$ group (Fig. 2A), and as well as in hFOB1.19 cells cultured in osteogenic induction medium in a time-dependent manner compared with control cells (Fig. 2B). The results indicated that GaN may activate the Akt signaling pathway in osteoblasts.

Construction and screening of TRPM7 siRNA. It has been reported that TRPM7 expression is associated with osteoblast ALP activity and osteogenesis following stimulation with magnesium ions (22). Therefore, it was hypothesized that TRPM7 may also serve a pivotal role in Ga ion-mediated regulation of osteoinduction in osteoblasts. To test the hypothesis, four different TRPM7-specific siRNAs were designed and constructed. MC3T3-E1 and hFOB1.19 cells were transfected with TRPM7 siRNAs for $72 \mathrm{~h}$. Subsequently, the membrane and total protein expression levels of TRPM7 were assessed via western blotting. Compared with the control and control siRNA groups, TRPM7 siRNA1, TRPM7 siRNA2 and TRPM7 siRNA3 notably decreased TRPM7 protein expression levels via siRNA-mediated knockdown in MC3T3-E1 cells (Fig. 3A and B). TRPM7 siRNA2 decreased TRPM7 protein expression to the lowest level in MC3T3 cells among the different TRPM7 siRNAs, and thus was selected for subsequent experiments. hFOB1.19 cells were transfected with TRPM7 siRNA1, TRPM7 siRNA2 or TRPM7 siRNA4. The results indicated that all three TRPM7 siRNAs decreased TRPM7 expression levels compared with the control and control siRNA groups. However, TRPM7 siRNA4 reduced TRPM7 protein expression to the lowest level among the different TRPM7 siRNAs in hFOB1.19 cells, so TRPM7 siRNA4 was selected for subsequent experiments (Fig. 3C and D). The results indicated the transfection efficiency of the TRPM7 siRNAs in the two osteoblast cell lines.

Ga ions promote ALP activity and calcium nodule formation by activating the TRPM7/Akt signaling pathway. To investigate whether Ga ion-mediated stimulation of ALP activity was associated with the TRPM7/Akt signaling pathway, osteoblasts were treated with TRPM7 siRNA or an Akt inhibitor (LY294002) to assess the effect on ALP activity. In MC3T3-E1 cells, ALP activity was significantly increased in GaN-treated cells cultured in osteogenic induction medium compared with cells cultured in osteogenic induction medium alone (Fig. 4A). However, GaN-induced ALP activity was significantly decreased by TRMP7 siRNA transfection or LY294002 treatment in MC3T3-E1 cells. For example, MC3T3-E1 cell ALP activity was 3-and 2.6-fold lower in TRPM7 siRNA-transfected and LY294002-treated cells compared with the osteoinduction $+\mathrm{GaN}$ group, respectively. Moreover, MC3T3-E1 cell ALP activity in the osteoinduction $+\mathrm{GaN}+$ control siRNA group was similar to the osteoinduction $+\mathrm{GaN}$ group. A 

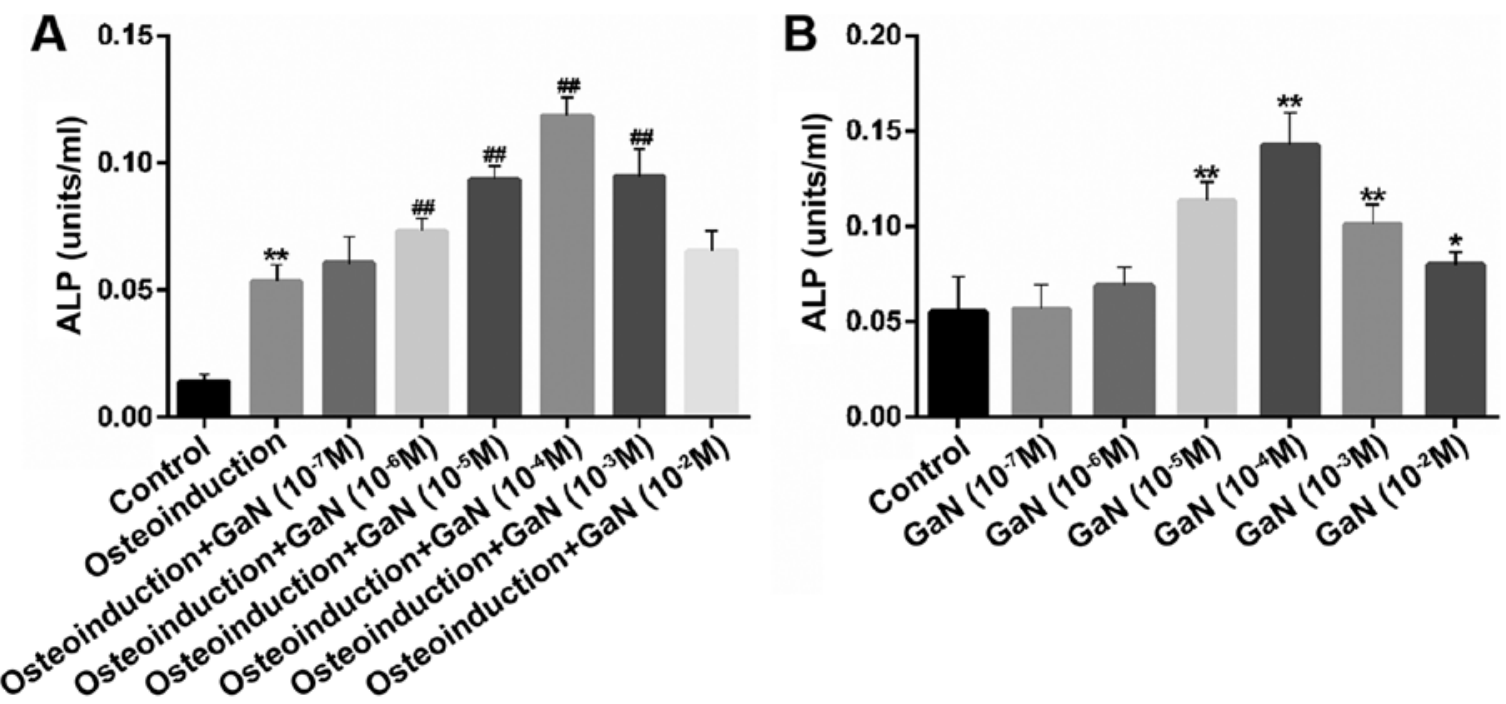

Figure 1. Effect of different Ga ion concentrations on MC3T3-E1 and hFOB1.19 cell ALP activity. ALP activity of (A) MC3T3-E1 and (B) hFOB1.19 cells following treatment with different concentrations of $\mathrm{GaN}$ for 7 days. ${ }^{*} \mathrm{P}<0.05$ and ${ }^{* *} \mathrm{P}<0.01$ vs. control; ${ }^{\# \#} \mathrm{P}<0.01$ vs. osteoinduction. Ga, gallium; ALP, alkaline phosphatase; GaN, gallium nitride.
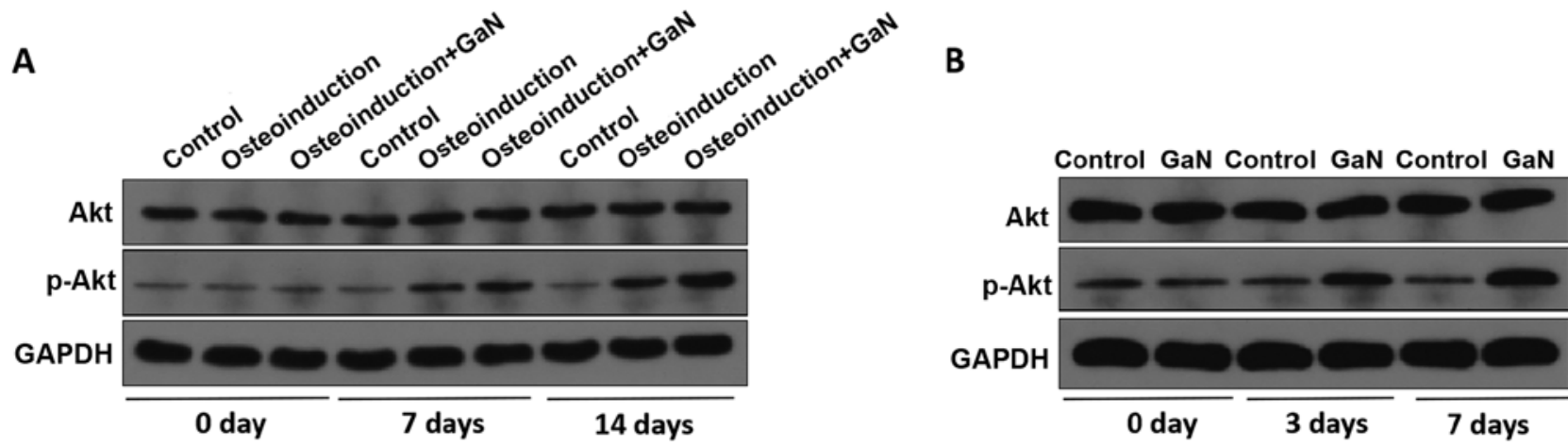

Figure 2. Effect of Ga ions on the Akt signaling pathway in MC3T3-E1 and hFOB1.19 cells. (A) Akt and p-Akt expression levels in MC3T3-E1 cells following treatment with $\mathrm{GaN}\left(10^{-4} \mathrm{M}\right)$ for 0,7 or 14 days. (B) Akt and p-Akt expression levels in hFOB1.19 cells following treatment with $\mathrm{GaN}\left(10^{-4} \mathrm{M}\right)$ for 0,3 or 7 days. $\mathrm{Ga}$, gallium; p, phosphorylated; GaN, gallium nitride.

similar pattern was observed in $\mathrm{hFOB} 1.19$ cells. $\mathrm{hFOB} 1.19$ cell ALP activity was significantly increased in GaN-treated cells compared with untreated cells. In addition, control siRNA transfection did not significantly alter the ALP activity of GaN-treated cells. By contrast, hFOB1.19 cell ALP activity was significantly decreased in the GaN + TRMP7 siRNA and GaN + LY294002 groups compared with the corresponding control groups (Fig. 4B). The results suggested that GaN promoted osteoblast ALP activity, whereas inhibition of the TRPM7/Akt signaling pathway inhibited osteoblast ALP activity.

Alizarin red staining was performed to assess calcium nodule formation, which is a hallmark of osteoinduction (23). The results suggested that osteogenic induction increased calcium nodule formation in MC3T3-E1 cells compared with control cells, which was further increased by $\mathrm{GaN}$ treatment. However, co-treatment with $\mathrm{GaN}$ and TRPM7 siRNA or LY294002 resulted in decreased calcium nodule formation compared with the osteoinduction $+\mathrm{GaN}$ group (Fig. 4C). The Alizarin red staining results were similar to the ALP activity results, suggesting that GaN may increase MC3T3-E1 cell osteogenic differentiation, whereas TRPM7 siRNA and LY294002 may inhibit osteogenic differentiation.

Ga ions upregulate osteogenic-related protein expression by activating the TRPM7/Akt signaling pathway. It has been reported that osteogenic-related proteins are regulated during osteogenesis and may be used to evaluate the osteoinduction of osteoblasts (28). The expression levels of osteogenic-related proteins (Runx2, Osterix, OCN, OPN, Akt and p-Akt) in MC3T3-E1 cells were assessed via western blotting. Following osteogenic induction, the protein expression levels of Runx2, Osterix, p-Akt, OCN and OPN were markedly increased compared with control cells, and the addition of $\mathrm{GaN}$ treatment further increased the expression levels of these proteins. By contrast, TRPM7 siRNA transfection and LY294002 treatment notably decreased the expression levels of osteogenic-related proteins in $\mathrm{GaN}$-treated cells cultured in osteogenic induction medium (Fig. 5A and B).

The expression levels of osteogenic-related proteins (MMP2, MMP9, Runx2, Akt and p-Akt) in 

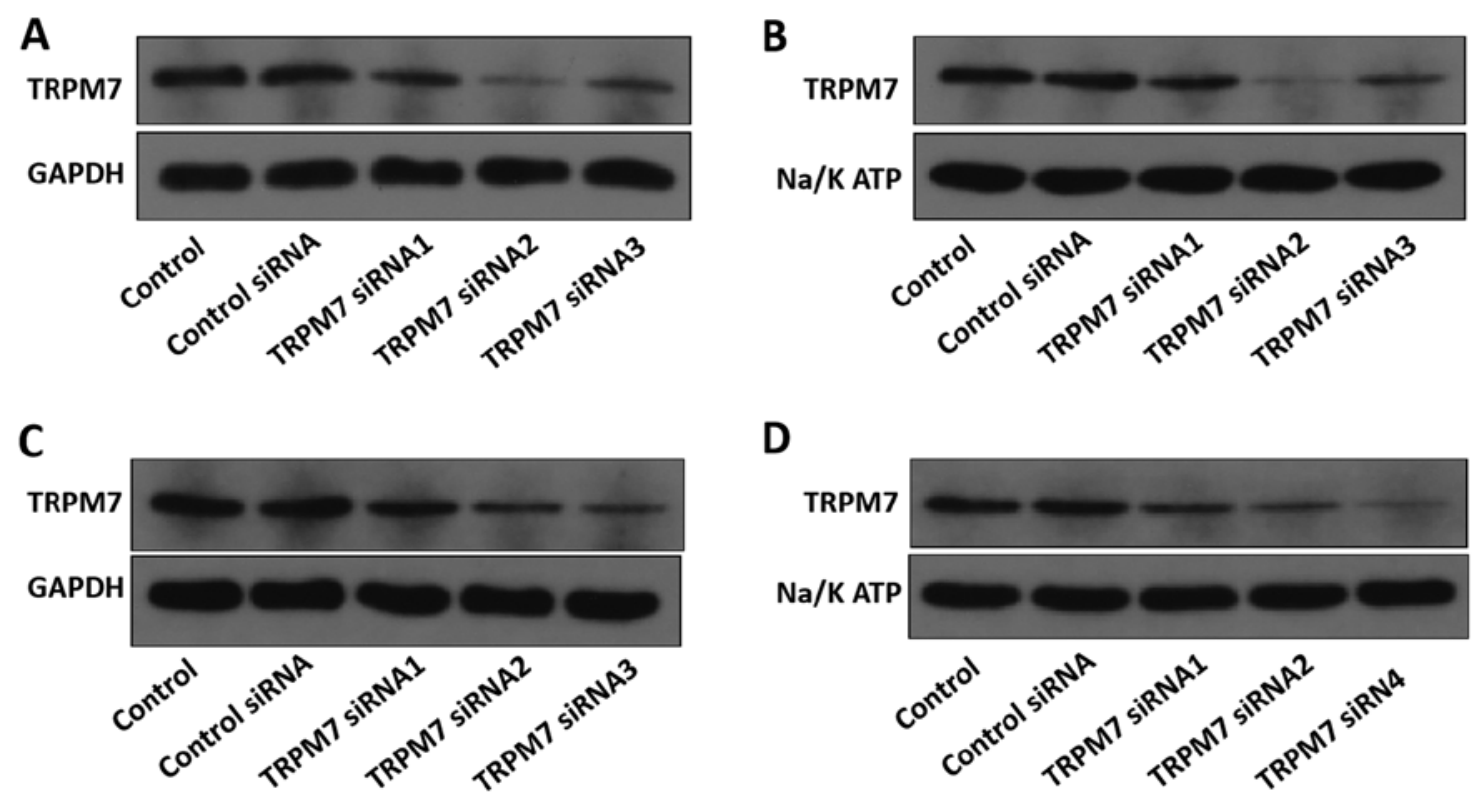

Figure 3. Effect of TRPM7 siRNAs on TRPM7 protein expression in MC3T3-E1 and hFOB1.19 cells. (A) Total and (B) membrane TRPM7 protein expression levels in MC3T3 cells following transfection with TRPM7 siRNAs. (C) Total and (D) membrane TRPM7 protein expression levels in hFOB1.19 cells following transfection with TRPM7 siRNAs. TRPM7, transient receptor potential melastatin 7; siRNA, small interfering RNA.

hFOB1.19 cells were also evaluated. In GaN-treated and GaN-treated + control siRNA-transfected cells, the expression levels of MMP2, MMP9, Runx2 and p-Akt were markedly higher compared with control cells, which suggested that $\mathrm{GaN}$ upregulated the expression of osteogenic-related proteins (Fig. 5C and D). However, TRPM7 siRNA transfection and LY294002 treatment decreased the expression levels of osteogenic-related proteins in GaN-treated hFOB1.19 cells. In addition, the mRNA expression levels of osteogenic-related proteins in the two cell lines were measured via RT-qPCR, and the results were similar to the western blotting results (Fig. 5F and G).

Furthermore, the intracellular expression of VEGF protein in hFOB1.19 cells was evaluated by performing an ELISA. Following treatment with GaN, the level of VEGF protein was significantly increased compared with control cells. Similar levels of VEGF expression were observed in the $\mathrm{GaN}+$ control siRNA and GaN groups (Fig. 5E). By contrast, VEGF protein levels were significantly decreased by TRPM7 siRNA transfection and LY294002 treatment in GaN-treated cells compared with the corresponding control groups.

The results suggested that $\mathrm{GaN}$ upregulated the expression levels of osteogenic-related proteins in human and mouse osteoblasts, thereby promoting osteoinduction. By investigating the underlying biological mechanisms, the results indicated that GaN-mediated osteoinduction was associated with the TRPM7/Akt signaling pathway, since TRPM7 knockdown and Akt inhibition markedly decreased the expression levels of osteogenic-related proteins in osteoblasts.

Effect of Ga ions on cell proliferation and apoptosis. To evaluate the application of Ga ions for biomedical treatment, the effect of $\mathrm{Ga}$ ions on cell proliferation and apoptosis was assessed. MC3T3-E1 cells were treated with GaN, TRPM7 siRNA or LY294002 for 0, 7 and 14 days. Subsequently, the
CCK-8 assay was performed to assess cell proliferation. After 7 and 14 days of culture, osteogenic induction significantly increased MC3T3-E1 cell proliferation compared with the control group. Following culture for 7 or 14 days, GaN treatment significantly increased MC3T3-E1 cell proliferation compared with the osteoinduction group (Fig. 6A). However, TRPM7 siRNA transfection and LY294002 treatment significantly inhibited cell proliferation in $\mathrm{GaN}$-treated cells cultured in osteogenic induction medium compared with the corresponding control groups. Similar results were observed for hFOB1.19 cells. Following culture for 3 or 7 days, hFOB1.19 cell proliferation was significantly increased in GaN-treated cells compared with control cells (Fig. 6B). There was no significant difference in cell proliferation between the $\mathrm{GaN}$ and $\mathrm{GaN}+$ control siRNA group. However, TRPM7 siRNA transfection and LY294002 treatment significantly decreased GaN-treated cell proliferation compared with the corresponding control groups. The results indicated that GaN promoted osteoblast proliferation, whereas TRPM7 siRNA and LY294002 inhibited cell proliferation.

To further investigate the cytotoxicity of GaN, cell apoptosis was evaluated. MC3T3-E1 cells were treated with GaN, TRPM7 siRNA or LY294002 for 0, 7 or 14 days, and cell apoptosis was evaluated by performing flow cytometry. The results demonstrated that GaN-treated cells cultured in osteogenic induction medium displayed a similar level of apoptosis compared with untreated cells cultured in osteogenic induction medium, which indicated that GaN did not significantly alter MC3T3-E1 cell apoptosis (Figs. 6C and S1). In addition, $\mathrm{GaN}$ treatment did not significantly alter hFOB1.19 cell apoptosis compared with the control group (Figs. 6D and S2). However, on day 7, following TRPM7 siRNA transfection or LY294002 treatment, hFOB1.19 cell apoptosis was increased in GaN-treated cells, although the difference between the 

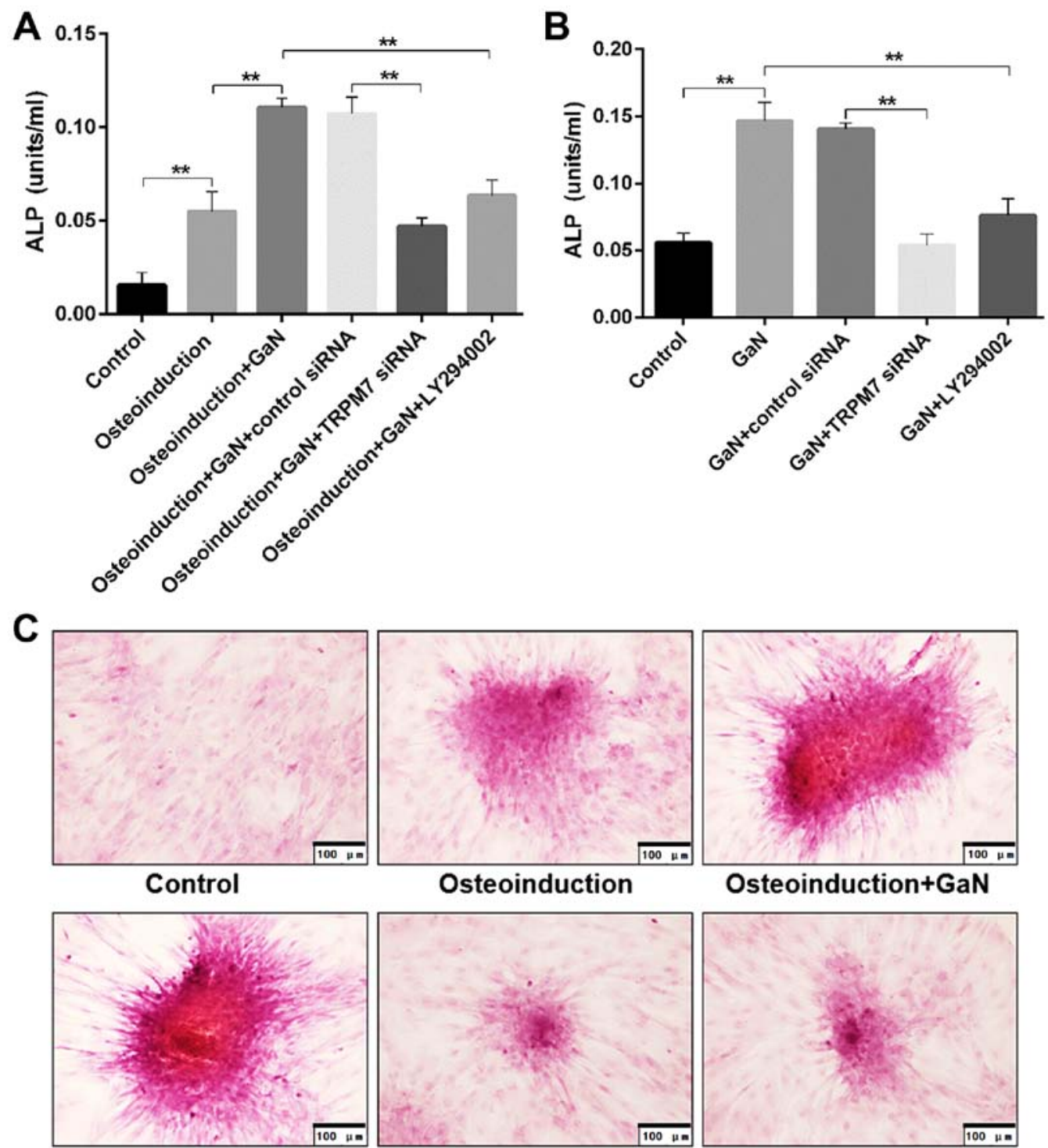

Osteoinduction+GaN +control siRNA

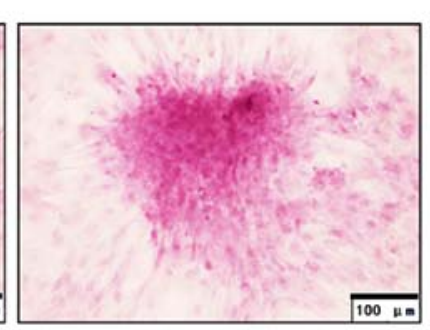

Osteoinduction

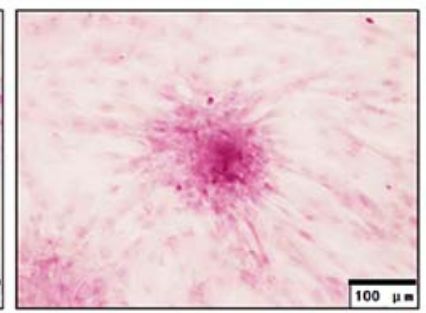

Osteoinduction+GaN +TRPM7 SIRNA

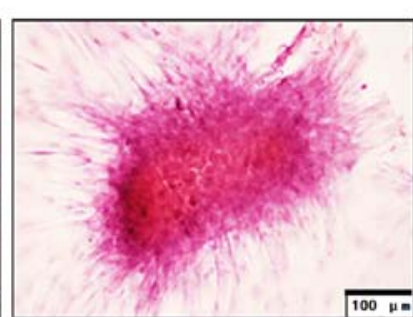

Osteoinduction+GaN

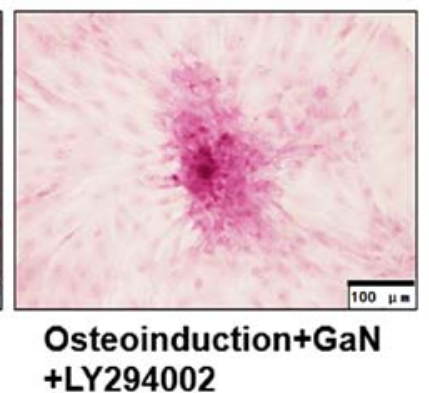

Figure 4. Effect of Ga ions on ALP activity and calcium nodule formation in MC3T3-E1 and hFOB1.19 cells. Cells were treated with GaN (10-4 M), with or without pre-treatment with TRPM7 siRNA (transfection for 96 h) or LY294002 (10 $\mu$ M). ALP activity of (A) MC3T3-E1 and (B) hFOB1.19 cells. (C) Representative images of Alizarin Red S staining of MC3T3-E1 cells (scale bar, $100 \mu \mathrm{m}$ ). ${ }^{* *} \mathrm{P}<0.01$. Ga, gallium; ALP, alkaline phosphatase; siRNA, small interfering RNA; GaN, gallium nitride; TRPM7, transient receptor potential melastatin 7.

groups was not significant. The results further indicated the biocompatibility of $\mathrm{Ga}$ ions, providing support for the biomedical application of $\mathrm{GaN}$.

Effect of Ga ions on cell migration. Osteoblast migration and invasion are physiological and pathological processes, which are crucial for maintaining the health and function of bone tissues $(3,29,30)$; therefore, it is necessary to maintain and promote the biological activity of osteoblasts during the treatment of osteoporosis. The effect of $\mathrm{Ga}$ ions on the migratory ability of osteoblasts was investigated by performing crystal violet staining. Compared with control cells, the migratory ability of hFOB1.19 cells was significantly increased in GaN-treated cells. Control siRNA transfection did not alter the migratory ability of GaN-treated cells; however, TRPM7 siRNA transfection and LY294002 treatment significantly reduced the migratory ability of GaN-treated cells compared with the corresponding control groups (Fig. 7A and B).

Effect of Ga ions on cell invasion. The cell invasion ability of hFOB1.19 cells was evaluated by performing crystal violet staining and quantified by cell counting. The invasion ability of GaN-treated cells and GaN-treated + control siRNA-transfected cells was significantly increased compared with control cells. However, GaN-induced cell invasion was significantly inhibited by TRPM7 siRNA-transfection and LY294002 treatment compared with the corresponding control groups. Cell invasion was increased by 3-fold in GaN-treated and GaN-treated + control siRNA-transfected cells compared with control cells. By contrast, following TRPM7 siRNA transfection or LY294002 treatment, the number of invading 

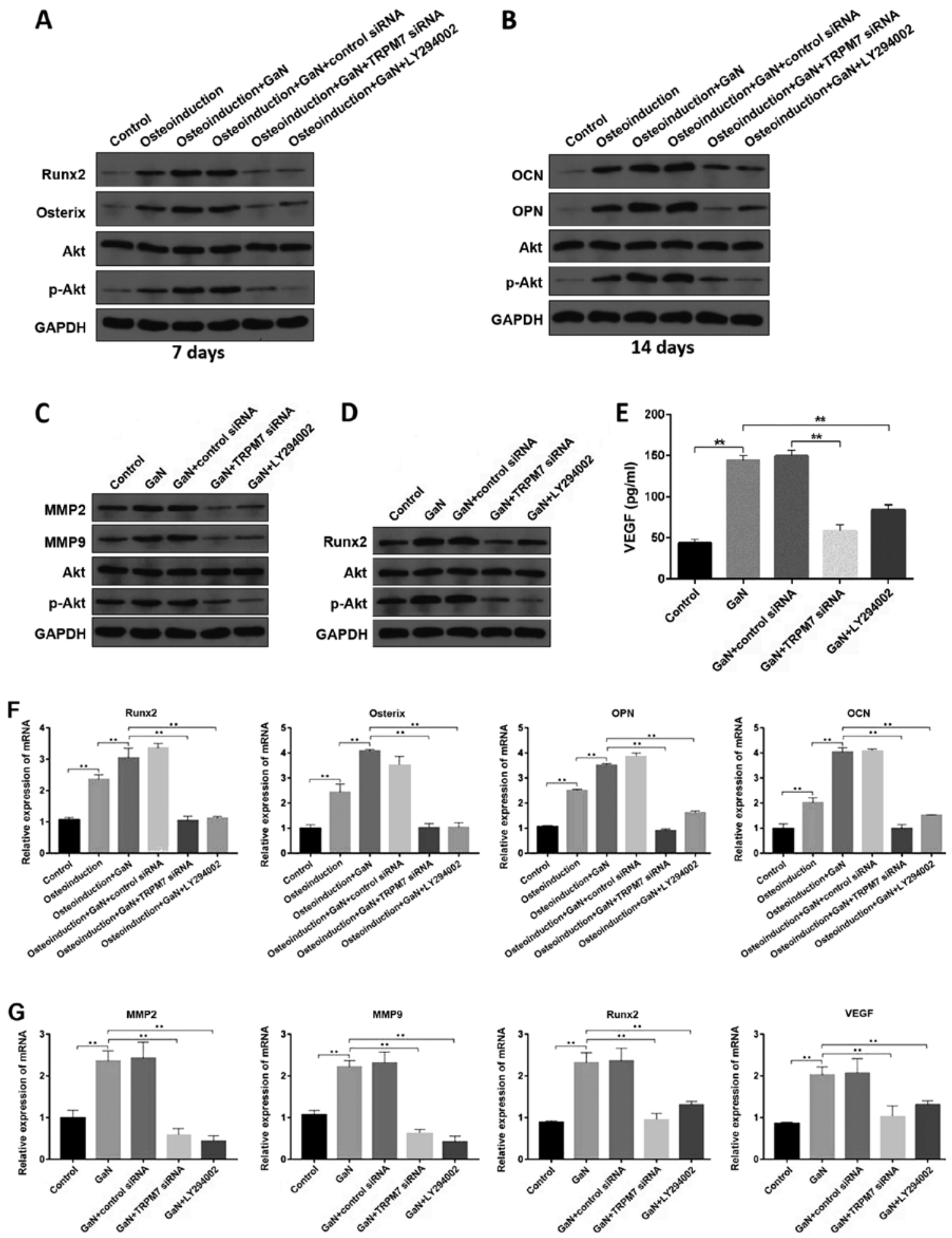

Figure 5. Effect of Ga ions on osteogenic-related protein expression in MC3T3-E1 and hFOB1.19 cells. Cells were treated with GaN (10-4 M), with or without pre-treatment with TRPM7 siRNA (transfection for $96 \mathrm{~h}$ ) or LY294002 (10 $\mu \mathrm{M})$. Protein expression levels of (A) Runx2, Osterix, Akt, p-Akt after 7 days, (B) OCN, OPN, Akt and p-Akt after 14 days in MC3T3-E1 cells. Protein expression levels of (C) MMP2, MMP9, Akt, p-Akt after 3 days, (D) Runx2, Akt and p-Akt after 7 days in hFOB1.19 cells. (E) Expression level of VEGF protein in hFOB1.19 cells. Akt and p-Akt were measured throughout the treatment process. (F) Relative mRNA expression levels of Runx2, Osterix, OPN and OCN in MC3T3-E1 cells. (G) Relative mRNA expression levels of MMP2, MMP9, Runx2 and VEGF in hFOB1.19 cells. ${ }^{* * *} \mathrm{P}<0.01$. Ga, gallium; Runx2, Runt-related transcription factor 2; p, phosphorylated; OCN, osteocalcin; OPN, osteopontin; GaN, gallium nitride; siRNA, small interfering RNA; MMP, matrix metallopeptidase; VEGF, vascular endothelial growth factor; TRPM7, transient receptor potential melastatin 7 .

cells was similar to the control group (Fig. 8A and B). The results suggested that $\mathrm{GaN}$ enhanced cell invasion, whereas cell invasion was inhibited in the absence of TRPM7 and Akt expression.

\section{Discussion}

Following the discovery of Ga compounds, they have been used for different biomedical applications; for example, 
A
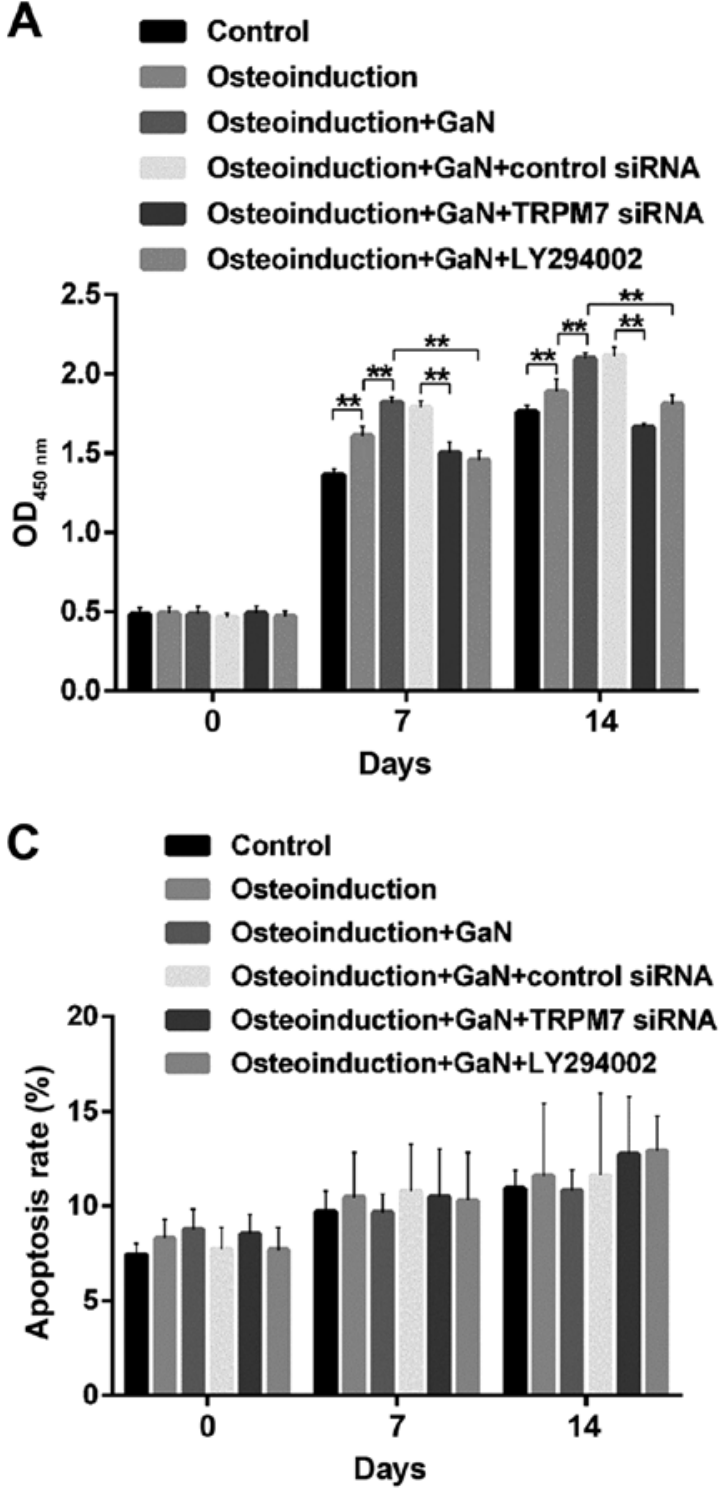

B

Control
GaN
GaN+control siRNA
GaN+TRPM7 siRNA
GaN+LY294002
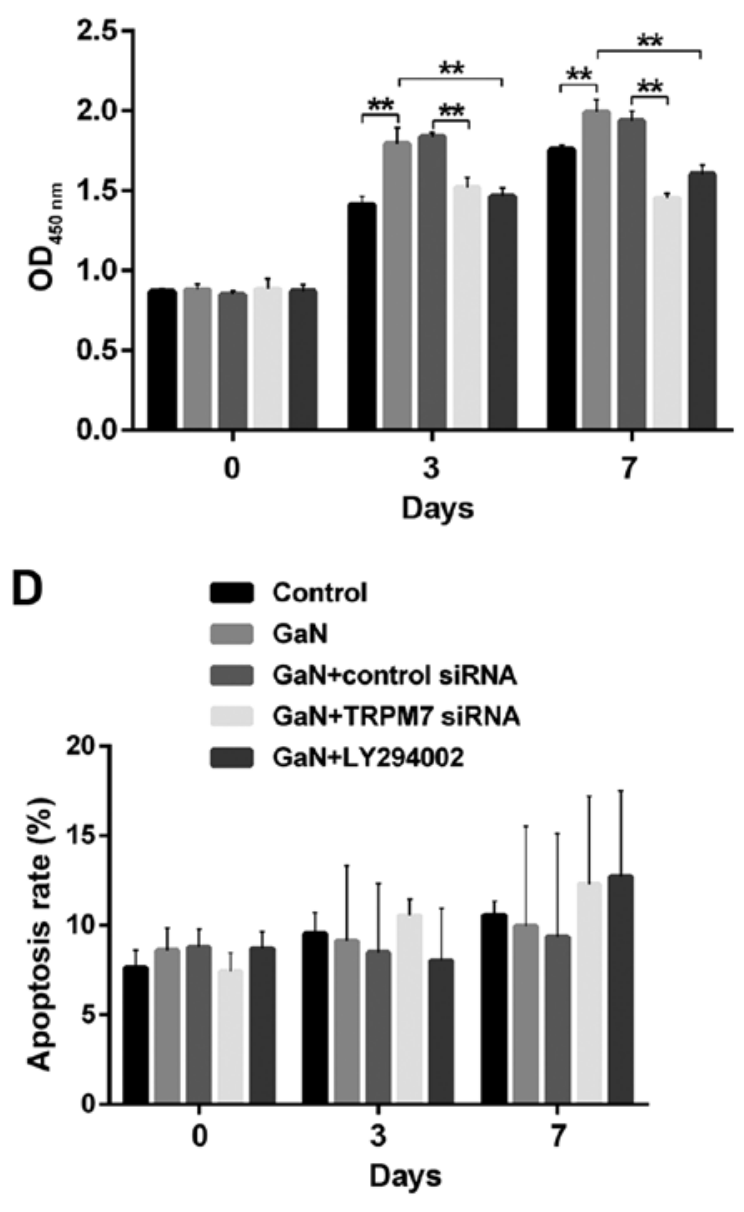

Figure 6. Effect of Ga ions on MC3T3-E1 and hFOB1.19 cell proliferation. MC3T3-E1 cells were treated with GaN $\left(10^{-4} \mathrm{M}\right)$, with or without pre-treatment with TRPM7 siRNA (transfection for $96 \mathrm{~h}$ ) or LY294002 $(10 \mu \mathrm{M})$ for 0,7 or 14 days. hFOB1.19 cells were treated with GaN $\left(10^{-4} \mathrm{M}\right)$, with or without pre-treatment with siRNA (siRNA transfection for $96 \mathrm{~h}$ ) or LY294002 $(10 \mu \mathrm{M})$ for 0,3 or 7 days. (A) MC3T3-E1 and (B) hFOB1.19 cell proliferation. (C) MC3T3-E1 and (D) hFOB1.19 cell apoptosis. ${ }^{* *} \mathrm{P}<0.01$. Ga, gallium; GaN, gallium nitride; siRNA, small interfering RNA; OD, optical density; TRPM7, transient receptor potential melastatin 7 .

gallium nitrate was found to reduce blood calcium levels and decrease bone turnover in patients with hypercalcium and Pagets disease (29). Ga compounds often display a high affinity for proliferating biological tissues, such as solid tumors (30). In addition, Ga possesses antineoplastic properties, similar to the chemical element platinum (3). The properties of Ga have attracted increasing attention in the field of cancer treatment research. To date, considerable antitumor efficacy has been achieved in inhibiting the growth of malignant lymphoma (31), melanoma (32) and epithelial ovarian cancer (33). In addition, $\mathrm{Ga}$ has been reported to accumulate into inflamed and infected sites, manifesting anti-inflammatory and immunosuppressive properties in animal models of human diseases (34). For example, the subcutaneous administration of GaN suppressed the development of a rat model of adjuvant arthritis (35). Furthermore, the bone affinity and antiresorptive activity of $\mathrm{Ga}$ indicated its potential therapeutic value in suppressing osteolysis and bone pain, which are associated with malignant bone tumors and bone metastases (6). However, the potential therapeutic applications of $\mathrm{Ga}$ in bone-related diseases have not been extensively investigated.

Osteoporosis is a common disease characterized by a systemic decrease in bone mass and disruption of microarchitecture. Due to an increased osteoclast population, or excessive osteoclast activity and decreased osteoblast activity in unhealthy bone sites, the treatment of osteoporosis may involve inhibition of osteoclast activity and/or promotion of osteoblast osteogenesis (19), However, few drugs with such actions are currently available. In a previous study, Ga ions inhibited the function and resorbing activity of osteoclasts in a dose-dependent manner (10); however, the effect of $\mathrm{Ga}$ ions on osteoblastogenesis was not investigated.

In the present study, Ga ions promoted the osteoinduction of both mouse and human osteoblasts, by enhancing ALP 
A

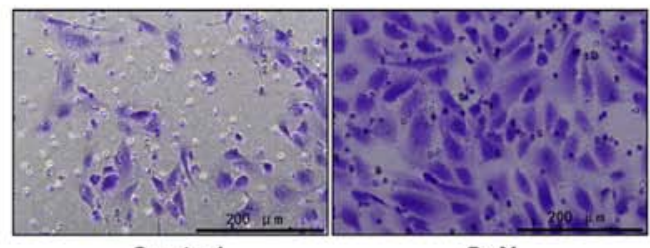

Control

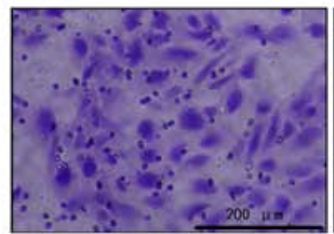

GaN+control siRNA

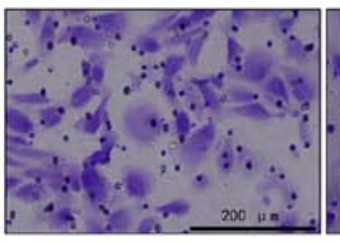

GaN+TRPM7 SiRNA
$\mathrm{GaN}$

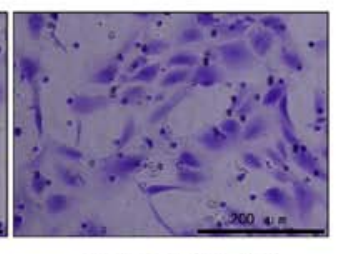

B

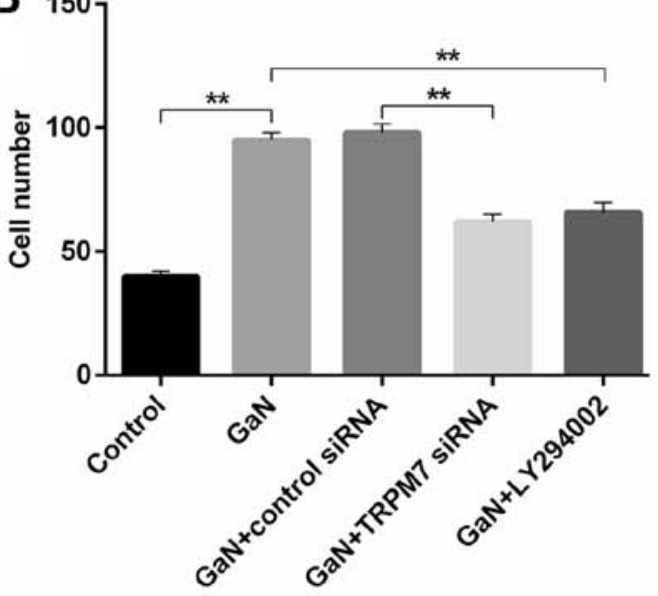

Figure 7. Effect of Ga ions on hFOB1.19 cell migration. hFOB1.19 cells were treated with GaN $\left(10^{-4} \mathrm{M}\right)$ for $24 \mathrm{~h}$, with or without pre-treatment with TRPM7 siRNA (transfection for $96 \mathrm{~h}$ ) or LY294002 $(10 \mu \mathrm{M})$. (A) Representative images of the Transwell migration assay (scale bar, $200 \mu \mathrm{m}$ ). (B) Quantification of cell migration. ${ }^{* *} \mathrm{P}<0.01$. Ga, gallium; GaN, gallium nitride; siRNA, small interfering RNA; TRPM7, transient receptor potential melastatin 7.

A

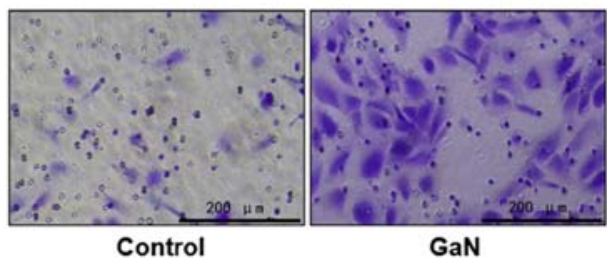

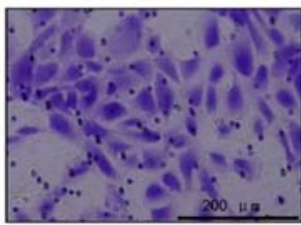

GaN+control siRNA

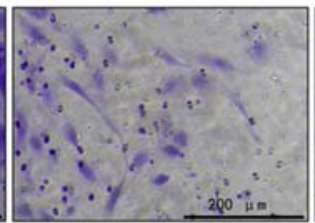

GaN+TRPM7 siRNA

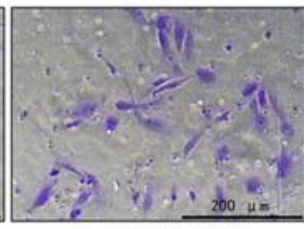

$\mathrm{GaN}+\mathrm{LY} 294002$
B

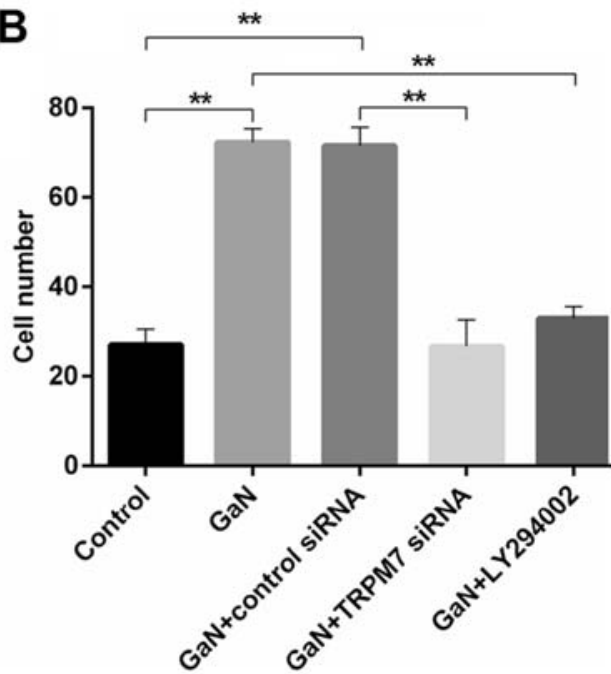

Figure 8. Effect of Ga ions on hFOB1.19 cell invasion. hFOB1.19 cells were treated with GaN (10-4 M) for 24 h, with or without pre-treatment with TRPM7 siRNA (transfection for $96 \mathrm{~h}$ ) or LY294002 (10 $\mu \mathrm{M})$. (A) Representative images of the Transwell invasion assay (scale bar, $200 \mu$ m). (B) Quantification of cell invasion. ${ }^{* *} \mathrm{P}<0.01$. Ga, gallium; GaN, gallium nitride; siRNA, small interfering RNA; TRPM7, transient receptor potential melastatin 7.

activity, calcium nodule formation and osteogenic-related protein expression. Mouse MC3T3-E1 cells are pre-osteoblasts and it has been suggested that osteoinduction $(50 \mathrm{mg} / \mathrm{ml}$ $\beta$-glycerophosphate and $10 \mathrm{mM} \mathrm{L-ascorbic} \mathrm{acid)} \mathrm{can} \mathrm{be} \mathrm{used}$ to promote the differentiation and maturation of the cells. By contrast, human hFOB1.19 cells are osteoblasts, so osteoinduction is not required (36). In the present study, Ga ions altered ALP activity in a concentration-dependent manner, increasing ALP activity to the highest level at a concentration of $10^{-4} \mathrm{M}$, which was considered as the optimal concentration for osteogenic differentiation of osteoblasts. However, a previous study reported that the optimal concentration of $\mathrm{Ga}$ ions for osteoclast inhibition was $100 \mathrm{mg} / \mathrm{ml}$ (10). The results suggested that osteoclast activity inhibition and promotion may not be achieved at the same dose. Controlled drug administration in a stepwise manner may serve as a viable strategy for effectively suppressing and promoting osteoclast activity for the treatment of osteoporosis.
Exploring the biological mechanisms underlying the positive effect of $\mathrm{Ga}$ ions on the osteoinduction of osteoblasts is important. TRPM7, a member of the transient receptor potential (TRP) protein family, is an ion channel protein with phosphate kinase activity, which is associated with cell proliferation and motility, and functions in various normal tissues (22,37-41). A previous study demonstrated that magnesium ions promoted osteoinduction of human osteoblasts via a TRPM7-related signaling pathway (22). Akt is a key signal transduction molecule in living systems, which can regulate cell proliferation, differentiation, apoptosis and glucose transport (42). Akt phosphorylation serves a key role in the osteogenesis of osteoblasts, as it can upregulate the Runx 2 gene, which induces the expression of genes associated with bone repair and reconstruction, such as $\mathrm{OCN}$, collagen I, OPN and ALP (43). Therefore, it was hypothesized that the TRPM7/Akt signaling pathway may also be involved in Ga ion-mediated osteoinduction in osteoblasts. Following 
TRPM7 knockdown and inhibition of Akt activity, ALP activity, calcium nodule formation, osteogenic-related protein expression in osteoblasts was significantly decreased. The results indicated that $\mathrm{Ga}$ ions promoted the osteoinduction of osteoblasts via the TRPM7/Akt signaling pathway. TRPM7 is a channel protein for magnesium and calcium ions (22). The specific interaction between TRPM7 and Ga ions requires further investigation. In the present study, the two cell lines were cultured for different lengths of time due to different cell characteristics, such as growth rate and the time of cell passage. For instance, regarding hFOB1.19 cells, the suggested observation window for ALP activity and calcium nodule formation is 3-7 days; however, for MC3T3-E1 cells, the observation window of ALP activity and calcium nodule formation is 7-14 days. Therefore, the osteogenic characteristics of hFOB1.19 and MC3T3-E1 cells were observed at three different time points.

In addition to osteoinduction, osteoblast proliferation and apoptosis was also assessed. Ga ions promoted human and mouse osteoblast cell proliferation without causing cell apoptosis, which indicated that GaN may ensure sufficient numbers and activity of osteoblasts for bone repair. Osteoblast migration and recruitment are physiological and pathological processes that are crucial for maintaining bone health and normal function (44-46). In the present study, Ga ions promoted human osteoblast migration and invasion. The unique biological characteristics of Ga ions identified in the present study may justify their therapeutic application for osteoporosis.

The present study had several limitations. Firstly, Alizarin Red S staining was only performed in the MC3T3-E1 cell line. Therefore, Alizarin Red S staining in the hFOB1.19 cell line should be conducted in future studies. Secondly, the two cell lines were observed at different time points; however, within each cell line, the time points were identical for the control and treatment groups. Thirdly, the present study examined the expression of different proteins related to pre-osteoblasts and osteoblasts. Pre-osteoblasts (MC3T3-E1) were used to study the effects of Ga ions on the expression levels of Osterix, OCN and OPN, whereas osteoblasts (hFOB1.19) were used for studying the effects of $\mathrm{Ga}$ ions on the expression levels of MMP2, MMP9, p-Akt, Runx2 and VEGF. Finally, the migration and invasion assays were not performed for MC3T3-E1 cells as they are pre-osteoblasts; therefore, future studies should investigate the effects of Ga ions on MC3T3-E1 cell migration and invasion. In addition, future studies should verify the results of the present study using an additional cell line.

In summary, the present study investigated the effect of $\mathrm{Ga}$ ions on the osteoinduction of osteoblasts and explored the underlying biological mechanisms. Ga ions increased intracellular ALP activity in a concentration-dependent manner. At the optimal concentration, $\mathrm{Ga}$ ions increased ALP activity, accelerated the formation of calcium nodules and upregulated the expression levels of osteogenic-related proteins in osteoblasts. Ga-mediated biological actions were associated with the TRPM7/Akt signaling pathway and were suppressed by inhibiting TRPM7 and p-Akt expression. In addition, $\mathrm{Ga}$ ions did not induce cell apoptosis, but promoted osteoblast proliferation, migration and invasion. To the best of our knowledge, the present study was the first to investigate the effects of $\mathrm{Ga}$ ions in osteoinduction of osteoblasts. Therefore, the results of the present study may provide a novel therapeutic strategy for osteoporosis and other bone-related diseases.

\section{Acknowledgements}

Not applicable.

\section{Funding}

The present study was supported by the Dalian Science and Technology Innovation Fund Project (grant no. 2018J11CY030), the Natural Science Foundation of China (grant nos. 81672139 and 81371942) and the Starting Fund for Doctor Talent Introduction of Affiliated Zhongshan Hospital of Dalian University (grant no. DLDXZSYY-BK201901).

\section{Availability of data and materials}

The datasets used and/or analyzed during the present study are available from the corresponding author on reasonable request.

\section{Authors' contributions}

DZ and YW designed the study. GG made substantial contributions to conception and design, and final approval of the version to be published. MY and DC performed the experiments. YZ analyzed the data. All authors read and approved the final manuscript.

\section{Ethics approval and consent to participate}

Not applicable.

\section{Patient consent for publication}

Not applicable.

\section{Competing interests}

The authors declare that they have no competing interests.

\section{References}

1. Salinas AJ, Shruti S, Malavasi G, Menabue L and Vallet-Regi M: Substitutions of cerium, gallium and zinc in ordered mesoporous bioactive glasses. Acta Biomater 7: 3452-3458, 2011.

2. Ma Z and Fu Q: Comparison of the therapeutic effects of yeast-incorporated gallium with those of inorganic gallium on ovariectomized osteopenic rats. Biol Trace Elem Res 134: 280-287, 2010.

3. Collery P, Keppler B, Madoulet C and Desoize B: Gallium in cancer treatment. Crit Rev Oncol Hematol 42: 283-296, 2002.

4. Warrell RP Jr, Bockman RS, Coonley CJ, Isaacs M and Staszewski H: Gallium nitrate inhibits calcium resorption from bone and is effective treatment for cancer-related hypercalcemia. J Clin Invest 73: 1487-1490, 1984.

5. Bockman RS: The effects of gallium nitrate on bone resorption. Semin Oncol 30: 5-12, 2003.

6. Warrell RP Jr and Bockman RS: Gallium in the treatment of hypercalcemia and bone metastasis. Important Adv Oncol 9: 205-220: 1989.

7. Bockman RS and Bosco B: Treatment of patients with advanced Pagets disease of bone with two cycles of gallium nitrate. Semin Arthritis Rheum 23: 268-269, 1994. 
8. Hall TJ and Chambers TJ: Gallium inhibits bone resorption by a direct effect on osteoclasts. Bone Miner 8: 211-216, 1990.

9. Blumenthal NC, Cosma V and Levine S: Effect of gallium on the in vitro formation, growth, and solubility of hydroxyapatite. Calcif Tissue Int 45: 81-87, 1989.

10. Verron E, Loubat A, Carle GF, Vignes-Colombeix C, Strazic I, Guicheux J, Rochet N, Bouler JM and Scimeca JC: Molecular effects of gallium on osteoclastic differentiation of mouse and human monocytes. Biochem Pharmacol 83: 671-679, 2012.

11. Makitie O: Causes, mechanisms and management of paediatric osteoporosis. Nat Rev Rheumatol 9: 465-475, 2013.

12. Rosen CJ and Bouxsein ML: Mechanisms of disease: Is osteoporosis the obesity of bone? Nat Clin Pract Rheumatol 2: 35-43, 2006.

13. Rivadeneira $\mathrm{F}$ and Mäkitie $\mathrm{O}$ : Osteoporosis and bone mass disorders: From gene pathways to treatments. Trends Endocrinol Metab 27: 262-281, 2016.

14. Hsu YH, Chen WY, Chan CH, Wu CH, Sun ZJ and Chang MS: Anti-IL-20 monoclonal antibody inhibits the differentiation of osteoclasts and protects against osteoporotic bone loss. J Exp Med 208: 1849-1861, 2011.

15. Kular J, Tickner JC, Pavlos NJ, Viola HM, Abel T, Lim BS, Yang X, Chen H, Cook R, Hool C, et al: Choline kinase $\beta$ mutant mice exhibit reduced phosphocholine, elevated osteoclast activity, and low bone mass. J Biol Chem 290: 1729-1742, 2015.

16. Rodriguez JES, Mansky KC, Jensen ED, Carlson AE, Schwarz T, Pham L, MacKenzie B, Prasad H, Rohrer MD, Petryk A and Gopalakrishnan R: Enhanced osteoclastogenesis causes osteopenia in twisted gastrulation-deficient mice through increased BMP signaling. J Bone Miner Res 24: 1917-1926, 2009.

17. Zhang D, Jing J, Lou F, Li R, Ping Y, Yu F, Wu F, Yang X, Xu R, $\mathrm{Li} \mathrm{F}$, et al: Evidence for excessive osteoclast activation in SIRT6 null mice. Sci Rep 8: 10992, 2018.

18. Theill LE, Boyle WJ and Penninger JM: RANK-L and RANK $T$ cells, bone loss, and mammalian evolution. Annu Rev Immunol 20: 795-823, 2002.

19. Cheng C, Wentworth K and Shoback DM: New frontiers in osteoporosis therapy. Annu Rev Med 71: 277-288, 2019.

20. Zhou J, Ye J, Zhao X, Li A and Zhou J: JWA is required for arsenic trioxide induced apoptosis in HeLa and MCF-7 cells via reactive oxygen species and mitochondria linked signal pathway. Toxicol Appl Pharmacol 230: 33-40, 2008.

21. Livak KJ and Schmittgen TD: Analysis of relative gene expression data using real-time quantitative PCR and the 2(-Delta Delta C(T)) method. Methods 25: 402-408, 2001.

22. Zhang X, Zu H, Zhao D, Yang K, Tian S, Yu X, Lu F, Liu B, Yu X, Wang B, et al: Ion channel functional protein kinase TRPM7 regulates $\mathrm{Mg}$ ions to promote the osteoinduction of human osteoblast via PI3K pathway: In vitro simulation of the bone-repairing effect of Mg-based alloy implant. Acta Biomater 63: 369-382, 2017.

23. Li J, Li JJ, Zhang J, Wang X, Kawazoe N and Chen G: Gold nanoparticle size and shape influence on osteogenesis of mesenchymal stem cells. Nanoscale 8: 7992-8007, 2016.

24. Yao Y, Shi X and Chen F: The effect of gold nanoparticles on the proliferation and differentiation of murine osteoblast: A study of MC3T3-E1 cells in vitro. J Nanosci Nanotechnol 14: 4851-4857, 2014.

25. Zhang Y, Kong N, Zhang Y, Yang W and Yan F: Size-dependent effects of gold nanoparticles on osteogenic differentiation of human periodontal ligament progenitor cells. Theranostics 7: 1214-1224, 2017.

26. Wang $\mathrm{C}$, Lin $\mathrm{K}$, Chang $\mathrm{J}$ and Sun J: Osteogenesis and angiogenesis induced by porous $\beta$-CaSiO3/PDLGA composite scaffold via activation of AMPK/ERK1/2 and PI3K/AKT pathways. Biomaterials 34: 64-77, 2013

27. Fang Y, Xue Z, Zhao L, Yang X, Yang Y, Zhou X, Feng S and Chen K: Calycosin stimulates the osteogenic differentiation of rat calvarial osteoblasts by activating the IGF1R/PI3K/AKT signaling pathway. Cell Biol Int 43: 323-332, 2019.

28. Ida-Yonemochi H, Nakagawa E, Takata H, Furuyashiki T, Kakutani R, Tanaka M and Ohshima H: Extracellular enzymatically synthesized glycogen promotes osteogenesis by activating osteoblast differentiation via AKT/GSK- $3 \beta$ signaling pathway. J Cell Physiol 234: 13602-13616, 2019.
29. Chitambar CR: Gallium and its competing roles with iron in biological systems. Biochim Biophys Acta 1863: 2044-2053, 2016.

30. Dudley H and Maddox G: Deposition of radio gallium (Ga72) in skeletal tissues. J Pharmacol Exp Ther 96: 224-227, 1949.

31. Chitambar CR, Purpi DP, Woodliff J, Yang M and Wereley JP: Development of gallium compounds for treatment of lymphoma: Gallium maltolate, a novel hydroxypyrone gallium compound, induces apoptosis and circumvents lymphoma cell resistance to gallium nitrate. J Pharmacol Exp Ther 322: 1228-1236, 2007.

32. Casper E, Stanton G, Sordillo P, Parente R, Michaelson R and Vinceguerra V: Phase II trial of gallium nitrate in patients with advanced malignant melanoma. Cancer Treat Rep 69: 1019-1020, 1985.

33. Malfetano JH, Blessing JA and Adelson MD: A phase II trial of gallium nitrate (NSC \#15200) in previously treated ovarian carcinoma. A gynecologic oncology group study. Am J Clin Oncol 14: 349-351, 1991.

34. Chitambar CR: Medical applications and toxicities of gallium compounds. Int J Environ Res Public Health 7: 2337-2361, 2010.

35. Matkovic V, Balboa AM, Clinchot D, Whitacre CC, Zwilling BS, Brown D, Weisbrode SE, Apseloff G and Gerber N: Gallium prevents adjuvant arthritis in rats and interferes with macrophage. Curr Ther Res 50: 255-267, 1991

36. Nomoto H, Maehashi H, Shirai M, Nakamura M, Masaki T, Mezaki Y, Park J, Aizawa M, Ohkawa K, Yoshida K and Matsuura T: Bio-artificial bone formation model with a radial-flow bioreactor for implant therapy-comparison between two cell culture carriers: Porous hydroxyapatite and $\beta$-tricalcium phosphate beads. Hum Cell 32: 1-11, 2019.

37. Fleig A and Penner R: The TRPM ion channel subfamily: Molecular, biophysical and functional features. Trends Pharmacol Sci 25: 633-639, 2004

38. Harteneck C: Function and pharmacology of TRPM cation channels. Naunyn Schmiedebergs Arch Pharmacol 371: 307-314, 2005.

39. Nadler MJ, Hermosura MC, Inabe K, Perraud AL, Zhu Q, Stokes AJ, Kurosaki T, Kinet JP, Penner R, Scharenberg AM and Fleig A: LTRPC7 is a Mg.ATP-regulated divalent cation channel required for cell viability. Nature 411: 590-595, 2001.

40. Runnels LW, Yue L and Clapham DE: TRP-PLIK, a bifunctional protein with kinase and ion channel activities. Science 291: 1043-1047, 2001

41. Schmitz C, Dorovkov MV, Zhao X, Davenport BJ, Ryazanov AG and Perraud AL: The channel kinases TRPM6 and TRPM7 are functionally nonredundant. J Biol Chem 280: 37763-37771, 2005.

42. Guntur AR and Rosen CJ: The skeleton: A multi-functional complex organ: New insights into osteoblasts and their role in bone formation: The central role of PI3kinase. J Endocrinol 211: 123, 2011.

43. Choi YH, Kim YJ, Jeong HM, Jin YH, Yeo CY and Lee KY: AKT enhances Runx2 protein stability by regulating Smurf2 function during osteoblast differentiation. FEBS J 281: 3656-3666, 2014.

44. Yu X, Huang Y, Collin-Osdoby P and Osdoby P: CCR1 chemokines promote the chemotactic recruitment, RANKL development, and motility of osteoclasts and are induced by inflammatory cytokines in osteoblasts. J Bone Miner Res 19: 2065-2077, 2004.

45. Neve A, Corrado A and Cantatore FP: Osteoblast physiology in normal and pathological conditions. Cell Tissue Res 343: 289-302, 2011.

46. Dirckx N, Van Hul M and Maes C: Osteoblast recruitment to sites of bone formation in skeletal development, homeostasis, and regeneration. Birth Defects Res C Embryo Today 99: 170-191, 2013.

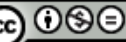

This work is licensed under a Creative Commons Attribution-NonCommercial-NoDerivatives 4.0 International (CC BY-NC-ND 4.0) License. 